\title{
HORACIO QUIROGA, PRECURSOR DE LA RELACIÓN CINE-LITERATURA EN LA AMÉRICA HISPÁNICA
}

Enriquecer las propias obras valiéndose de lo que pertenece al mundo de las artes, es tendencia destacada en autores hispanoamericanos, y el cine, a pesar de un muy difundido comercialismo, es una de ellas. Pero mientras las manifestaciones de otras artes visuales resultan relativamente accesibles para quien estudie sus relaciones con la literatura, hasta hace muy poco no ocurría lo mismo con lo referente al cine. Una abundante y con frecuencia excelente bibliografía, la edición cuidadosa de guiones y sobre todo la reaparición de las películas mismas en videocassettes han transformado la zona vedada en mina de información. Limitar, sin embargo, la influencia del cine a texto e imagen sería lamentable. El mundo de la cinematografía con sus técnicas, actores, efectos sobre el público y locales de proyección forma parte no desdeñable de ella. Sin intenciones de agotar el tema, trataré de mostrar algunas respuestas a la atracción desafiante del séptimo arte y su universo; pero por razones obvias, y por otras que se verán más adelante, centraré mi trabajo en torno a un autor cuya importancia, aunque quizá no su influencia, es indudable.

Hombre de variados intereses y preocupaciones ${ }^{1}$, Horacio Quiroga (1878-1937) vivió durante el periodo más notable del cine mudo y los primeros años del sonoro, si bien este último parece haberle disgustado ${ }^{2}$. Lo que pensaba, sentía o imaginaba bajo su influjo sobrevive en cuatro cuentos ${ }^{3}$, y en algunas críticas

1 Vale la pena destacar que la fotografía, parienta inmóvil del cine, figuró entre ellos, como lo prueba "La cámara oscura" (1920).

${ }^{2}$ NoÉ JITRIK, Horacio Quiroga. Una obra de experiencia y riesgo, Arca, Montevideo, 1967, p. 46.

3 "'Miss Dorothy Phillips, mi esposa" (1919), recogido en Anaconda (1921); “El espectro"' (1921), en El desierto (1923-1924); “El puritano"' (1926) y "El vampiro"' (1927), ambos en Más allá (1935). 
que desgraciadamente no he leído ${ }^{4}$. A pesar de nuevas tendencias, y acaso sin saberlo, autores recientes coincidirían con sus huellas, probándonos, una vez más, que lo totalmente nuevo bajo el sol no pasa de quimera.

De los cuatro cuentos, "Miss Dorothy Phillips, mi esposa" (1919/1921) se caracteriza por su riqueza de sugerencias aprovechadas. La historia, ingenua pero muy de acuerdo con las fantasías y reacciones del público masculino ante la magnificada presencia de las estrellas en la pantalla, narra la experiencia onírica de Guillermo Grant, especie de alter ego de Quiroga que reaparece en "El espectro"' y "El vampiro"'. Si resolver al final de una película que todo lo ocurrido ha sido un sueño es recurso común para terminar con una nota feliz - y satisfactoria para el espectador - lo que de otra manera debería haber concluido en forma muy distinta ${ }^{5}$, el desenlace feliz de "'Miss Dorothy..."' está en el sueño mismo, no en la realidad del personaje:

Pero esto es un sueño. Punto por punto, como acabo de contarlo, lo he soñado... No me queda sino para el resto de mis días su profunda emoción, y el pobre paliativo de remitir a Dolly el relato - como lo haré en seguida-, con esta dedicatoria.

" A la señora Dorothy Phillips, rogándole perdone las impertinencias de este sueño, muy dulce para el autor'"6.

Quienes hayan leído las últimas obras de Julio Cortázar no dejarán de sorprenderse ante la similitud de sentimientos, si no de actitud, entre los experimentados por Grant-Quiroga y los expues-

${ }^{4}$ Los comentarios aparecieron en las revistas Atlántida (1922), El Hogar y Caras y Caretas (1927), todas de Buenos Aires. A la misma actividad se dedicarían también más tarde tanto Jorge Luis Borges como Alejo Carpentier.

${ }^{5}$ Ejemplo típico de ello es The avenging conscience o "Thou shalt not kill" (1914), dirigida por Griffith e inspirada en "The tell-tale heart" y "Annabell Lee"' de Poe; cf. William K. Everson, American silent film, Oxford University Press, New York, 1978, p. 77; Tom Milne, Paul Willemen et al., The Encyclopedia of Horror Movies, Harper \& Row, New York, 1986, p. 18. Se encuentra completa en Video Yesteryear, Connecticut, núm. 463. Hay otro caso parecido en The despoiler (1915), donde la presencia de Enid Markey (cf. infra) puede indicar un conocimiento preciso por parte de Quiroga (cf. Robert Connelly, The Motion Picture Guide, t. 10, Silent Film, Chicago, CineBooks, p. 61, col. 2).

${ }^{6}$ Anaconda, $2^{\mathrm{a}}$. ed., Babel, Buenos Aires, s.a., p. 205. 
tos en "Queremos tanto a Glenda" y muy especialmente en "Botella al mar [Epílogo a un cuento]"' ' Y se sorprenderán más aún al enterarse de que, como Glenda Jackson en nuestros días ${ }^{8}$, Dorothy Phillips en los suyos fue también una actriz, que verdaderamente actuó con un ya olvidado William Stowell y con Lon Chaney - a veces con ambos simultáneamente, a veces con uno u otro de ellos-, y que algunas de sus películas fueron $A$ Doll's House (1917) y The Grand Passion (1918), como también Hell Morgan's Girl (1917) y The Risky Road (1918), llamada Lola Morgan y Sendero de espinas en el cuento (pp. 177, 181, 183, 189, 196) ${ }^{9}$, apuntando quizá con las dos últimas a un problema del cual Quiroga hablaría más tarde en "El espectro".

Todavía hay más circunstancias reales en esta fantasía onírica inspirada por sentimientos igualmente reales. Además de Barbara La Marr y Marion Davies, fácilmente identificables aún, todas las actrices mencionadas fueron también seres de carne y hueso ${ }^{10}$. Anticipándose por una parte a su actividad posterior de crítico y por otra tratando de consolidar un ambiente, Quiroga introduce referencias a los aficionados al cine (pp. 159, 161-162, $170,182)$, a las rivalidades entre las empresas cinematográficas (p. 178), a las peculiaridades de la filmación y la interpretación frente a las cámaras (pp. 180-181), a las diferencias de actuación en Norteamérica, Hispanoamérica y Europa (pp. 182-183), a las concesiones al público y a su influencia en la fama de que goza el séptimo arte (p. 182).

Lo que Quiroga no dice abiertamente, sin embargo, es que el cuento pretendía ser un guión o que le faltaba muy poco para serlo, hecho que se sugiere tres veces (pp. 193, 203 y 204). Ya sin disimulos intentaría años más tarde el nada fácil paso a tal

${ }^{7}$ Julio Cortázar, Queremos tanto a Glenda, La Oveja Negra-Nueva Imagen, Bogotá, 1980, pp. 17-24; Deshoras, Nueva Imagen, México, 1983, pp. 11-17.

${ }^{8}$ IAN WOODWARD, Glenda Jackson. A study in fire and ice, St. Martin's Press, New York, 1985

${ }^{9}$ Everson, op. cit., p. 187; Ephraim Katz, The Film Encyclopedia, Perigee Books, New York, 1982, p. 910, col. 2; Motion Picture Guide, películas con Stowell y Chaney, pp. 84, 233, 327, 341, 348, 353, 355, 395, 396, 418 y 424, películas mencionadas en el cuento, pp. 236, 341, 355, 360 .

${ }^{10}$ Cf. KATZ, op. cit., p. 271 (Miriam Cooper); p. 292 (Grace Cunard); p. 535 (Mildred Harris); p. 542 (Wanda Hawley); p. 678 (Alice Lake); p. 980 (Edith Roberts). En cuanto a Brownie Vernon, cuyo primer nombre era Agnes, y "Brownie" sólo un sobrenombre, figura con uno u otro, o con ambos, en un largo catálogo de películas mudas de las cuales sólo se da el reparto ( $\mathrm{Mo}$ tion Picture Guide, pp. 326, 329, 332, 346, 348, 362, 383, 399, 416, 418, 434). 
forma, frecuente hibridación de lo literario y lo técnico; pero $L a$ jangada florida quedó - ¿sigue? - inédita y no realizado el proyecto de adaptar "La gallina degollada" (Jitrik, p. 46). Con todo, como algunos de sus relatos poseen peculiaridades que los productores apreciaron, la fusión de "Una bofetada", "Los pescadores de vigas", "Los mensú" y "Los destiladores de naranja" se convirtió en Prisioneros de la tierra (1938-1939), una de las pocas películas' argentinas verdaderamente destacadas ${ }^{11}$. Escritores más recientes intentarían el mismo paso. A María Luisa Bombal se debe el guión de La casa del recuerdo (1940) y el de su propia obra La última niebla, que nunca llegó a filmarse ${ }^{12}$. Jorge Luis Borges y Adolfo Bioy Casares colaboraron en dos infortunadas tentativas: Los orilleros y El paraíso de los creyentes (Buenos Aires, Losada, 1955). Alejo Carpentier cortejó el documental en Le Vaudou (ca. 1934). Juan Rulfo publicó tres "textos para cine", pero parece dudar bastante en cuanto a la forma apropiada de un guión: "El gallo de oro" es esencialmente un cuento, "El despojo" añade unas pocas indicaciones técnicas y "La fórmula secreta" es sin más un poema ${ }^{13}$. Gabriel García Márquez, quien había adquirido entrenamiento cinematográfico en Roma y dirigió en México, además de participar en El gallo de oro escribió por lo menos otros cuatro guiones: uno se basa en "La viuda de Montiel" (1979); el segundo, Eréndira (1983) ${ }^{14}$, no se limita a "La increíble y triste historia de la cándida Eréndira y de su abuela desalmada" sino que añade "Muerte constante más allá del amor"; acerca de los dos restantes, citados en inglés, prefiero no especular ${ }^{15}$.

${ }^{11}$ También se filmó otra película basada en "Su ausencia" (Más allá). Aunque tuve oportunidad de verla en Buenos Aires cuando se estrenó, no recuerdo ni el título ni la fecha. Por lo demás, no pasaba de ser un esfuerzo meritorio. 49-51.

12 José Gómez-Sicre, "La escritora en la niebla", Amer, 1981, núm. 2,

${ }^{13}$ Juan Rulfo, "El gallo de oro" y otros textos para cine, Era, México, 1980. El primero se filmó en 1964 (hay videocassette en Madera Cinevideo, CA, 1985). Según los créditos, sin embargo, el cinedrama se debe a Carlos Fuentes, Gabriel García Márquez y Roberto Gavaldón; sólo la idea original se atribuye a Rulfo. Si comparamos su texto con el de la película, encontramos diferencias indudables. Una adaptación más próxima al texto de Rulfo se filmó en 1986 con el nombre de El imperio de la fortuna; cf. 1988. The Motion Picture Annual, CineBooks, Inc., Evanston, IL, p. 194.

${ }^{14}$ Media Home Entertainment, Los Ángeles, CA, CC8001, 1985.

${ }^{15}$ Cfi. James Monaco, Who's who in American film now [1975-1986], updated ed. Zoetrope, New York, 1987, pp. 26-27. Por lo que pueda valer, cito los dos títulos que ofrecen dudas: Mary my dearest (1982) y Time to die (1985). 
Rasgos señalados en "Miss Dorothy..." pasaron a "El espectro" (1921/1924) y "El puritano" (1926/1935) ${ }^{16}$, sobre todo al primero. Aunque en distinto grado, en ambos persistirá la atribución de nombres identificables a los personajes femeninos. Es verdad que en "El espectro" la protagonista sólo es llamada Enid; pero así lo fueron también dos actrices bien conocidas por entonces: Enid Bennett, famosa por su interpretación de Lady Marian Fitzwalter en Robin Hood (1922), y muy especialmente Enid Markey, compañera de William S. Hart por lo menos en The fugitive or The taking of Luke McVane (Video Yesteryear, núm. 962) y The Darkening Trail, ambas de 191517. En la versión de "El puritano", aparecida en La Nación de Buenos Aires (11 de julio de 1926), la protagonista ostenta el nombre completo de Norma Shearer, que en el libro cede su lugar al simple pronombre Ella, a la vez intencionadamente vago y misteriosamente evocativo. Para dar una idea de "las hondas virtudes de interpretación viril" que caracterizan a su Duncan Wyoming, Quiroga lo compara con el famoso William S. Hart, renovador del Western y estancado luego: "Hart ha dado ya al cine todo lo que podíamos esperar de él, y es un astro que cae" ("El espectro", p. 67) ${ }^{18}$; por contraste alude a lo que no posee un actor despectivamente ni siquiera mencionado pero que sin duda es Tom Mix, "el empalagoso héroe actual"19. Echando mano descriptivamente de dos recursos muy utilizados en el cine -el avance progresivo de la imagen y el primer plano absoluto- y de la impresión que ambos provocan en el espectador, Quiroga muestra el instante que un ya muerto $W$ yoming elige para iniciar el cumplimiento de un malévolo propósito (p. 73). La por muchos años frecuente y harto fácil combustión de las películas en plena proyección, hecho que a la vez sobresaltaba e irritaba al público, sirve dramáticamente para interrumpir el avance del vengativo personaje y al mismo tiempo para confirmar el inminente peligro en que se encuentran Enid y Grant (p. 75). La referencia a la costumbre de cambiar los títulos de los films por

${ }^{16}$ El desierto, Losada, Buenos Aires, 1966, pp. 66-78; Más allá, Lautaro, Buenos Aires, 1952, pp. 85-92.

${ }^{17}$ Everson, op. cit., pp. 120 y 122; Katz, op. cit., p. 105, col. 2; Michael R. PitTs, Western movies, Mac Farland \& Co., Jefferson (NG) \& London, 1986, p. 95, núm. 768.

${ }^{18}$ Cf. Everson, op. cit., pp. 240, 242-244, 247-250; KATZ, op. cit., p. 537.

${ }^{19} \mathrm{Cf}$. George N. Fenin y William K. Everson, The western from silents to the Seventies, Grossman Publishers, New York, 1973, pp. 74, 107 y 108-121; EVERSON, op. cit., pp. 242, 244, 250; KATZ, op. cit., pp. 815-816. 
razones muchas veces puramente comerciales y que todavía acarrea perjuicios de localización, indica la mayor dificultad que se opone a los proyectos de la pareja para escapar del limbo en que se encuentran (p. 78). Finalmente, el temor expresado por Wyoming antes de morir acerca del "desamparo moral" de Enid en el "infierno del cine" (p. 68) y la alusión a las "fastuosas orgías" de Hollywood ("Puritano", 8) recuerdan sin duda circunstancias verdaderas, como los escándalos que tanto perjudicaron las carreras de Roscoe "Fatty" Arbuckle, Mary Miles Minter y Mabel Normand (Everson, 296-297; Katz, 40-41, 812 y 864).

“El espectro", "El puritano" y "El vampiro" (1927/1935, Más allá, pp. 19-45) se diferencian de "Miss Dorothy..." en un punto esencial que para nada aparece en el cuento de 1919. Según él, la imagen humana captada y retenida por las películas no sólo es el actor ${ }^{20}$ sino que es más vital y poderosa que el actor mismo hasta el punto de adquirir una inmortalidad que puede ser realmente maligna. Quiroga atribuye esta supervivencia y sus características a principios químicos y vibraciones que al afectar la imagen afectan también la índole original del intérprete. Bajo esta explicación seudocientífica quizá yazga la razón verdadera: la impresión profunda e inquietante que causa en los espectadores el ver eternamente vivos a quienes han muerto $\mathrm{ya}^{21}$. Tampoco debería descartarse en relación con ello la idea del doble que tanto ha frecuentado las creencias populares y ciertas creaciones literarias ${ }^{22}$, y que en 1913 dio lugar a la primera versión cinematográfica de El estudiante de Praga ${ }^{23}$. Es curioso que el tema de la inmortalidad por la imagen tentara tan poco a otros escritores his-

${ }^{20}$ La idea de que la imagen es el actor y que por eso está viva ha pasado por otras imaginaciones - la de Richard Pryor y la mía, por ejemplo- durante la niñez. Woody Alien da cinematográficamente un paso más: si la imagen representa lo mejor de la voluntad interpretativa, esto puede concederle vitalidad autónoma (cf. The purple rose of Cairo, 1985).

${ }^{21}$ Vale la pena consignar un caso preciso. El crítico de La Poste (París, 1985), que había asistido a un programa presentado por los hermanos Lumière, se convenció de que con el nuevo invento la muerte no sería ya "absoluta, final" (David ShIPMAn, The story of cinema, St. Martin's Press, New York, First U.S.A. edition, 1984, p. 18, col. 1).

${ }^{22}$ Otтo Rank, Don Juan, une étude sur le double, trad. S. Lautman, Denoël et Steele, Paris, 1932.

${ }^{23}$ Der Studen von Praq, Alemania, 1913. La dirigió Stellan R ye y fue protagonizada por Paul Weneger. Hay videocassette (Tamarelle's International Films, Chico, CA). 
panoamericanos contemporáneos. El único que se interesó vivamente en ella, según parece, fue Adolfo Bioy Casares en su novela La invención de Morel (1940); pero lo proyectado por complicadas máquinas carece de independencia y voluntad propia, $y$, si interfiere con la realidad, es por mero accidente.

Los tres cuentos acogen también la idea de que las imágenes de los actores pueden ver al público y destacar a algunos de sus miembros, sea por los sentimientos existentes entre ellos ("El espectro", "El puritano"), sea porque los últimos son asiduos concurrentes a las salas de espectáculos ("El vampiro"). Así, Duncan Wyoming buscará con la mirada a Grant y a Enid hasta localizarlos; la suicida de "El puritano" verá noche tras noche al hombre por quien se ha matado y, más poderosa en la muerte que en la vida, lo atraerá al extraño ultramundo en que se encuentra; la creatura extraída de las películas en "El vampiro" confesará haber reconocido instantáneamente a Grant por haberlo visto muchas veces mientras éste asistía a la proyección de sus films. Tal idea no encontró eco, que yo sepa, en escritores hispanoamericanos. Ha vuelto a aparecer, sin embargo, y acaso independientemente, en la deliciosa The purple rose of Cairo de Woody Allen (1985). En ella, un personaje no sólo advierte la presencia asidua de una mujer, sino que le habla desde la película, y, deseoso de ver el mundo, abandona la pantalla, provocando la interrupción del filme y una reacción semejante de sus imágenes en todas las copias existentes. Esta magnificación, que tanto nos recuerda lo que ocurre a Duncan Wyoming, va aún más allá: acompañada por el fugitivo, viva y sólo por un tiempo, la asidua espectadora entrará en el ambiente de las sombras cinematográficas, a la manera, aunque con evidentes diferencias, del final de " $\mathrm{El}$ puritano".

Si en "El espectro" el primer plano absoluto del rostro de Wyoming proviene sin duda de un cliché frecuente en los films de William S. Hart (Fenin-Everson, p. 87), la complicada venganza que aquél lleva a cabo contra Enid y Grant parece inspirada en un pasaje de Stolen voice (1915), donde la inesperada presencia de un actor en la pantalla determina un ataque cardiaco en el espectador que lo ha privado de su voz (Motion Picture Guide, p. 271, col. 1). Las diversas etapas de transformación por las que pasa la creatura de "El vampiro" sugieren vivamente la influencia general o parcial de determinadas películas. Lo que Rosales logra al principio de sus esfuerzos es "una de esas cosas que deben quedar para siempre del otro lado de la tumba"' (p. 33); desde 1910, films 
inspirados en Frankenstein ${ }^{24}$ habían utilizado el tema de los experimentos blasfemos y del horror que sus resultados causan en los más o menos dementes experimentadores. Todavía durante la primera etapa, Rosales ve que su reciente creación se esfuerza por subir a la cama donde él se encuentra (p. 33); una espeluznante secuencia de $D r$ Jekyll and $M r H y d e(1920)$ quizá nos indique su origen: la ascensión lenta, pero finalmente lograda, de una monstruosa araña a la cama del doctor ${ }^{25}$. La coronación de los trabajos de Rosales es una hermosísima mujer que, para sobrevivir, necesita la sangre del creador y que termina aniquilándolo. No creo aventurado suponer que el rasgo adquirido por la creatura al final de su evolución y el destino último del imprudente Rosales derivan de la conjunción de dos sugerencias: la casi impuesta por el influyente y aclamado Nosferatu de Murnau (1921-1922) ${ }^{26}$ y la propuesta por la demoniaca protagonista de la Alraune de 1918 (Milne-Willemen, p. 21).

Aunque no muchos se interesaron en aprovechamientos semejantes, los tres que hasta ahora he encontrado merecen atenta consideración. Cuando por primera vez tuve oportunidad de ver el Vampyr de Dreyer (1931) ${ }^{27}$, me sorprendió la similitud entre algunas de sus secuencias y pasajes de La amortajada (1938) de María Luisa Bombal. Recuérdese que, al comenzar la novela, los ojos de la muerta protagonista, yacente en su cama, se entreabren, y quienes la velan se inclinan para mirarla, "sin saber que Ella los veía... sentía"'28; casi al final, durante el trayecto desde su habitación hasta la cripta donde será depositada, "ve oscilar el cielo raso... Una enorme rasgadura. . . De pronto el cielo sobre sí. . . se siente entrar en la gran calle de árboles. . . vienen luego a su encuentro los macizos eucaliptos . . Ahora la llevan a campo tra-

${ }^{24}$ Cf. Milne-Willemen, op. cit., Frankenstein (1910); Life without soul (1916), p. 20; Il mostro di Frankenstein (1920), p. 28.

${ }^{25}$ Se trata de la versión dirigida por John S. Robertson y protagonizada por John Barrymore (hay videocassette en Blackhawk Films, Devenport, IO). Cf. también Milne-Willemen, op. cit., p. 26.

${ }^{26}$ Cf. ibid., pp. 21 y 29-30. Puede leerse el cinedrama en Masterworks of the German cinema, Icon Editions, Harper \& Row Publishers, New York (etc.), 1973, pp. 52-95. La versión más completa en videocassette (87 minutos) es hasta ahora la publicada por Video Yesteryear (núm. 530). Hay otra de 52 minutos en Blackhawk Films.

${ }^{27}$ El cinedrama está incluido en Carl Theodor Dreyer. Four screenplays, Indiana University Press, Bloomington \& London, 1970, pp. 77-126. Hay también videocassette, aunque no muy buena, en Hollywood Home Theatre, 1980.

${ }^{28}$ María Luisa Bombal, La amortajada, Orbe, Santiago de Chile, 1969, p. 7. 
viesa... De pronto un muro... el cementerio y el panteón de la familia" (pp. 115-122). En Vampyr el doble del doble del protagonista - ¿o el triple de éste? - yace con los ojos abiertos en un ataúd, a través de cuya mirilla ve a otros personajes de los cuales uno por lo menos se inclina sobre él; mientras lo transportan al camposanto, distingue cielosrasos, detalles de esos cielosrasos, que "pass rhythmically over his field of vision. The open sky and branches; he is being carried out of the house, round the church, out of the village, away across the fields" (pp. 117-119). Tanto o más que esta similitud, me sorprendió que nadie hubiera hablado de ella. Tal circunstancia me llevó, no a dudar de mi hallazgo, sino a permanecer prudentemente callada hasta que alguien o algo de algún modo confirmara mi opinión. Después de leer el artículo de Gómez-Sicre (cit. en n. 12) me siento infinitamente mejor. Éste indica que María Luisa Bombal era muy aficionada al cine, que había asistido al "rodaje de la Juana de Arco de Carl-Theodor Dreyer" y que, "como periodista", lo había entrevistado (p. 49). Lo que probablemente nunca sabremos con exactitud es precisamente cuándo y cómo se estableció el contacto entre Vampyr y La amortajada, aunque el porqué quizá no necesite explicaciones.

Al estudiar las fuentes de El reino de este mundo de Alejo Carpentier encontré que ninguna, al referirse a los espejos de Sans Souci, indicaba su reunión en un lugar preciso, como ocurre en la novela ${ }^{29}$. Creo que la solución del problema está en la adaptación cinematográfica del The Emperor Jones de Eugene O'Neill $(1933)^{30}$, protagonizada por Paul Robeson, a quien mucho admiraba Carpentier ${ }^{31}$. En la película, e inmediatamente después de apoderarse del mando de la isla donde se ha refugiado, Jones contempla la pobreza del salón principal de la casa de gobierno. Un único espejo refleja su imagen y esto lo decide a anunciar cambios. El último propósito se expresa con vehementes exclamaciones: "And then I want mirrors! Plenty of them!' Una secuencia posterior muestra que dicho propósito se ha realizado. Mientras Jones, vestido con galas napoleónicas, avanza lentamente hacia el trono, tres espejos rectangulares y luego tres ovalados repiten su satisfecha figura. Aunque nada de esto aparece en la obra ori-

29 Emma Susana Speratti-Piñero, Pasos hallados en "El reino de este mundo'', El Colegio de México, 1981.

${ }^{30}$ Embassy Home Entertainment, Los Ángeles, CA (Classic Collection, núm. 6084), 1987.

31 Alejo Carpentier, La consagración de la primavera (1978), en Obras completas, t. 7, Siglo XXI, México, 1985, pp. 145-154, 269. 
ginal de O'Neill, hay algo de ella que se recoge con extrema fidelidad en la película y que no puede haber dejado indiferente a Carpentier: el estruendo ascendente de un enorme tambor que se inicia poco antes de la fuga de Jones y sólo se interrumpe al sonar los estampidos que anuncian su muerte. ¿Será éste el origen del pasaje en El reino donde "los tambores todos del vodú" empujan vigorosamente el ataque a Sans Souci?32

Tan aficionado al cine como Carpentier, Julio Cortázar no ha perdido oportunidad de hacérnoslo saber. En Rayuela, y por boca de su alter ego Morelli, llegó a decirnos qué actores y directores habían influido en él ${ }^{33}$, y uno de los mencionados es René Clair. Aunque desgraciadamente no conozco todas sus películas, creo haber encontrado una influencia precisa en Sous les toits de Paris $(1929)^{34}$. Dos amigos, que resuelven problemas y diferencias jugando a los dados, ven en un café a una mujer que los atrae y deciden aplicar una vez más su sistema. Uno de los dados cae al suelo, rueda y queda entre los pies de otra mujer sentada a una mesa. Sin mucha cortesía, el más atrevido de los amigos busca el dado en el peligroso lugar donde se encuentra. ¿Quién, aun sin haber visto la película, dejará de asociar lo anterior con el episodio del terrón de azúcar en Rayuela (pp. 22-23)?

Aunque Cortázar admiraba a Quiroga y compartía con él un franco entusiasmo por el cine, las diferencias que los separan no pueden ser mayores. Ambos coinciden, sin embargo, con distintos grados de propósito e intensidad, en un tema que quizá haya rondado también a otros autores: el de que estar en una sala de cinematógrafo contribuye a no del todo imprevistas revelaciones. Que en "El espectro" predomine lo fantástico no invalida el hecho de que tanto Enid como Grant sienten de algún modo que han traicionado a Wyoming mereciendo así una justificada venganza y de que su obsesiva asistencia a las proyecciones de la última película del muerto desencadena lo que les cuesta la vida. Dos personajes de Cortázar tendrán también su oscura noche del alma: el primero en "La banda"' 35 , el segundo en Libro de Manuel36.

32 Alejo Carpentier, El reino de este mundo (1949), en ibid., t. 2, pp. 95-96.

33 Julio Cortázar, Rayuela, Sudamericana, Buenos Aires, 1963, p. 412.

${ }^{34}$ Hay videocassette en Video Yesteryear, núm. 441.

35 Apareció inicialmente en Final del juego, Los Presentes, México, 1956, pp. 112-120. Se recogió más tarde en Relatos, Sudamericana, Buenos Aires, 1970, pp. 439-444.

36 Julio Cortázar, Libro de Manuel, Sudamericana, Buenos Aires, 1973, cf. especialmente pp. 101-103 y 279. 
Pero si en esencia circunstancia y resultado se asemejan tanto en el cuento como en la novela - ambos personajes están en un cine y cobran allí su particular conciencia sociopolítica一, no ocurre lo mismo con el tratamiento. La realidad habitual predomina en "La banda", donde el protagonista va efectivamente al cine con la intención de ver una vieja película de Litvak. En Libro de Manuel, en cambio, lo onírico sirve de marco a la experiencia del personaje, quien en un sueño trata de asistir a la proyección de un film de Fritz Lang. En los dos casos, la película es lo de menos, puesto que ni siquiera se la nombra, aunque de ella se den algunas características: la de Litvak es ya vieja; la de Fritz Lang es de misterio, presenta "una escena en un tribunal" y posiblemente incluye en el título la palabra "medianoche" (pp. 101-102)37. Pero si en "La banda" nada se nos dice de la influencia del local en el personaje, la novela es explícita: "cuántas cosas empiezan para nosotros en un cine o en un ómnibus ${ }^{38}$... andá a saber si los cines, bien mirado, date cuenta de que la fatiga visual nos vuelve más receptivos, aunque en este caso yo solamente soñaba" (p. 270).

El problema de Horacio Quiroga en cuanto precursor de la relación cine-literatura en la América Hispánica radica en que los cuatro cuentos donde la introdujo son bastante desconocidos tanto por los admiradores como por los detractores de su obra. Elogios y censuras se han limitado casi siempre a los cuentos misioneros; todo lo demás parece no existir. A causa de esto, dije al principio que Quiroga era importante, pero no influyente, en el cultivo de la relación estudiada, a pesar de que lo hizo con la imaginación y el entusiasmo de todo buen aficionado al cine. Y como en la América Hispánica la afición al cine es una de las más intensas y arraigadas, nada tiene de raro que otros escritores reencontraran independientemente lo que Quiroga había ofrecido años antes en sus desdeñados cuentos.

Emma Susana Speratti-Piñero Wheaton College, Massachusetts

${ }^{37}$ Con los datos proporcionados por Cortázar la identificación es prácticamente imposible, especialmente en lo que se refiere a Litvak. En cuanto a Fritz Lang, tengo la impresión de que Cortázar más ha tratado de despistarnos que de iluminarnos o ha combinado intencionadamente situaciones de varios films.

${ }^{38} \mathrm{La}$ reunión del cine y el ómnibus en el texto apunta directamente a dos cuentos políticos de los primeros tiempos del autor, donde la revelación es lo esencial. Uno es por cierto "La banda"; el otro es justamente "Ómnibus" (Bestiario, Sudamericana, Buenos Aires, 1951, pp. 51-68; Relatos, pp. 59-71). 